\title{
Effects of scopolamine on inhibitory mechanisms*
}

\author{
CURTIS L. GRAF \\ State University of New York, Stony Brook, New York 11790
}

\begin{abstract}
Scopolamine-injected rats remained withdrawn from a novel chamber longer than controls under free exploratory conditions (Ss could withdraw into the home cage). This finding was interpreted to mean that scopolamine prevented the habituation of fear induced by the novel chamber. Under forced exploratory conditions (Ss had no opportunity to withdraw), scopolamine-injected rats showed: (1) continuous general motor behavior rather than a within session decrease as found in control rats; (2) as much within session decrease in locomotion, scanning, and object contact as did controls. These results were interpreted to mean that scopolamine produced a disinhibitory effect on general motor activity without interfering with behavioral response habituation. It was further suggested that the drug's disinhibitory effect on fear and general motor activity is due to the impairment of an inhibitory cholinergic system within the brain, but that this same cholinergic system does not mediate the inhibitory process underlying behavioral response habituation.
\end{abstract}

Carlton (1963) proposed that two hypothetical arousal-regulating mechanisms control normal activation and inhibition. The excitatory mechanism is generally believed to be the reticular formation of the brain stem, which is under adrenergic control (Magoun, 1963). The nature of the inhibitory mechanism is much less certain. Carlton (1968, 1969, 1971) suggested that the cholinergic system (brain-acetylcholine) mediates the inhibitory process underlying habituation and has investigated the idea by using centrally active anticholinergic drugs such as scopolamine and atropine.

This theory was supported by experiments in which exploratory behavior failed to habituate in drugged rats and mice. In these experiments, the following measures were taken: (1) responsiveness to a novel chamber (measured by running time) following preexposure under the influence of an anticholinergic drug (Carlton \& Vogel, 1965); (2) choice behavior in a novel T-maze while under the effects of an anticholinergic drug (Meyers \& Domino, 1964; Douglas \& Isaacson, 1966; Squire, 1969; Leaton, 1968, 1969); (3) effects of an anticholinergic drug on light-reinforced barpressing (Carlton, 1966) and on the frequency of nose insertions (Wakeley \& O'Sullivan, 1969). The results of these experiments support the hypothesis that anticholinergic drugs attenuate habituation to novelty.

In contrast, Warburton and Groves (1969) directly measured the effects of scopolamine on habituation of the acoustic startle response in rats and found that, although amplitude was increased by scopolamine, drugged animals showed as much habituation as nondrugged animals. This finding is inconsistent with the hypothesis that a inhibitory cholinergic system mediates response habituation, at least habituation of the acoustic startle response.

The present experiments were designed to investigate

*This study was supported in part by NSF Grant 31-8301A The author is indebted to California State University, Los Angeles, for the use of their facilities and to Roger Schvaneveldt, Annette Ehrlich, and John Haralson for help ful criticisms and suggestions. further the idea that the cholinergic system functions as an inhibitory mechanism. The aim was to reconcile the conflicting results of experiments cited by Carlton with the findings of Warburton and Groves. The present investigation measured the effects of scopolamine on exploratory behavior, but a more detailed behavioral analysis was carried out than has been done heretofore.

It has been well established that a novel chamber initially elicits increased activation and investigatory behavior. As duration of exposure to the chamber increases, a decline in investigatory behavior typically occurs. This decline is considered to result from habituation to novel aspects of the chamber. Welker (1957, 1959) first clearly showed that this typical decrease in behavior was motivated by fear induced by the novel chamber and not by curiosity. In his experiments, rats were exposed to a novel chamber under one of two motivational conditions: (a) free exploration, in which animals were given freedom of choice to enter the chamber or remain in a small darkened box; (b) forced exploration, in which animals did not have an opportunity to withdraw. The results showed that under free conditions rats initially remained outside the chamber, but after increased exposure the animals showed a continuous rate of locomotor activity rather than the typical sharp decline in activity found under forced conditions. These results were recently replicated by Valle (1972) who, like Welker, concluded that fear, induced by the novel chamber, habituates under free conditions but inhibits the locomotor activity of animals under forced conditions.

In the experiments to be reported here, naive rats were given scopolamine and exposed to a novel chamber under either free exploratory conditions (Experiment I) or forced exploratory conditions (Experiment II), which provided a test for the following two possibilities: (1) that the cholinergic system is involved in the habituation of fear under free conditions; (2) that the cholinergic system is involved in behavioral response habituation under forced conditions. The hypothesis was 
that the cholinergic system may inhibit a general arousal system within the brain without mediating behavioral response habituation.

\section{EXPERIMENT I FREE EXPLORATION}

Experiment I was designed to examine the possibility that reduced cholinergic activity in the brain may interfere with the habituation of fear, indicated by avoidance of the novel chamber, in a free exploratory situation. If so, then rats under the influence of socpolamine should remain outside the novel chamber for a greater period of time than control rats. In order to assess any possible effects of the drug on exploratory behavior within the chamber, a continuous verbal account of each animal's behavior was dictated on magnetic tape. Behavior was described by means of seven behavioral categories. As in other experiments of this type (e.g., Warburton \& Groves, 1969; Carlton \& Vogel, 1965), a 2-day procedure was used with drug injections occurring on Day 1 only.

\section{Method}

Subjects. Ss were 16 naive male hooded rats of the Long-Evans strain which were bred in the laboratory at California State University at Los Angeles. They were weaned at the age of 31 days and were housed from then on in groups of six. Starting from the same age, Ss were handled extensively and were afforded the opportunity to explore in groups in a large wooden chamber containing ladders, running wheel and various objects. One day prior to the experimental procedure, each $\mathrm{S}$ was individually housed. The animals were maintained on ad lib food and water throughout the entire experiment. Mean weight for the group at the start of the experiment was $322 \mathrm{~g}$.

Apparatus. The experiment was conducted in a testing room located near the animal laboratory. The room was lit by a $25-\mathrm{W}$ red bulb, hung 24 in. from the floor of the apparatus. A white noise generator, located outside but near the apparatus, was used to mask extraneous auditory stimuli. The apparatus was a chamber $(18 \times 18 \times 13$ in.) constructed of $1 / 2$-in. plywood and

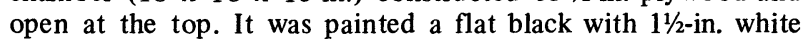
stripes on all four walls. The floor was divided into nine equal sections by white lines and numbered with white letters. There were five wooden spools ( 1 x 3 in.) attached to the chamber walls and painted flat white. The spools, hung either 2 or 5 in. from the chamber floor, served as exploratory objects. An opening $\left(3 \frac{1 / 2}{\mathrm{in} .}{ }^{2}\right)$ at floor level in one of the chamber walls could be opened or closed by a guillotine-type door attached outside the chamber through which Ss could enter the apparatus from the home cage. A tape recorder was used to record E's verbal description of S's behavior while in the chamber. The animals were clearly observable through the open top of the chamber but were not visible in the home cage.

Procedure. Preliminary results showed that rats refused to enter the chamber on the first day of exposure (cf. Welker, 1957). Therefore, two procedures were added to ensure Ss' entry on Day 1; first, four decoy rats were thoroughly familiarized with the chamber and were trained to eat from a food dish temporarily placed in the chamber. One decoy rat was placed in the home cage of each naive $S 1 \mathrm{~h}$ before testing, where it remained with $S$ until both were given access to the chamber. The second procedure was a 5-min forced exposure to the chamber one day prior to the experiment. All Ss were given a normal saline injection, carried in the home cage to the testing room, and placed directly into the chamber. After a 5-min exposure, the entry door was opened, allowing each $S$ to retreat to its home cage. Both procedures were used with all Ss.

Test Day 1. Ss were randomly assigned either a normal saline injection or one of three doses of scopolamine hydrobromide $(0.25,0.50$, or $1.00 \mathrm{mg} / \mathrm{kg} \mathrm{IP})$. A decoy rat was placed in each S's home cage $1 \mathrm{~h}$ before injection. After injection, $S$ and the decoy rat were carried in the home cage to the testing room and the cage was placed in position. After $20 \mathrm{~min}$, the entry door was opened, allowing the decoy rat and $S$ to enter the chamber. Within 30 sec after S's entry, the decoy rat and food dish were removed, which marked the beginning of the 14-min test session. Retreat to the home cage was possible at any time.

Test Day 2. The procedure was identical to that of Test Day 1, except that no injections were given and no decoy rats were used. Each $S$ was carried in its home cage to the testing room, and after $20 \mathrm{~min}$ allowed free access to the chamber for the 14-min test session.

There were four Ss in each dosage level. The four dosage groups were designated Group C (control), Group S (small-.25 dose), Group $M$ (medium-.50 dose) and Group L (large-1.0 dose).

Behavioral Analysis. The response categories were based on preliminary observations and were similar to those used by Bindra and Spinner (1958), Grant and Mackintosh (1963), and Welker (1964). The response categories, code names, and descriptions were as follows:

Locomotion (Lo) A floor section number was recorded every time the rat's front feet moved from one floor section to another; an index of movement within the chamber.

General Motor $(\mathrm{Gm})$ Diffuse motor activity while on all four limbs; includes sniffing (rapid movement of whiskers, nose twitching, heavy breathing), head movements (left-right, up-down, stretch), and body movements; attention is directed to the walls and floor of the chamber.

Scan (Sc) Sniffing and head movements while in an upright posture either supported or unsupported by front feet; attention is directed to distant surroundings.

Object Contact (Ob) Any movement (e.g., sniffing, licking) which involves contact with any one of the five objects other than by chewing. Freeze (Fr) The rat remains rigidly motionless, possibly
sniffing.

Groom (Gr) A licking or scratching of any part of the body.

Chew (Ch) The rat mouths any part of the chamber.

Other A left-over category of possible responses such as scanning without sniffing, gnawing on bits of food, etc.

The response categories were both exhaustive and mutually exclusive, except for Lo and $\mathrm{Gm}$, in which case Lo took precedence over $\mathrm{Gm}$. The code name for each behavior was dictated on the magnetic tape as each $S$ performed it. The rate of response recording was about 1 to 2 per second, which generated no more than 1,680 observations for the $14-\mathrm{min}$ session. The observations looked like this after the tapes were transcribed: ... Gm, Gm, Gm, 7, Gm, 8, 9, Sc, Sc, Ob, Fr ... The tapes were then replayed in parallel with a stopwatch, so 2-min intervals could be timed. In addition to the behavioral observations, the total amount of time each $S$ remained in the home cage, or retreat time, was measured by a standard stopwatch. Retreat and reentry into the chamber were defined by the movement of the rat's forequarters into either compartment. 


\section{Results and Discussion}

Retreat Time. All Ss entered the chamber within 2 min, except for one Group S and one Group L animal, who entered within $5 \mathrm{~min}$. After the decoy rat was removed and recording began, the control Ss retreated to the home cage about $35 \%$ of the total session time on Day 1 and on Day 2. In contrast, the drugged Ss retreated $83 \%$ of the session time on Day 1 , but only $37 \%$ of the time on Day 2. Figure 1 shows the total number of minutes each $S$ remained in retreat during Days 1 and 2 (each bar denotes the value obtained from a single rat). A two-way analysis of variance based on these times revealed significant dosage $(F=13.0, \mathrm{df}=$ $3 / 12, \mathrm{p}<.01)$, day $(\mathrm{F}=77.4, \mathrm{df}=1 / 12, \mathrm{p}<.01)$ and interaction $(\mathrm{F}=8.66, \mathrm{df}=3 / 12, \mathrm{p}<.01)$ effects. Subsequent one-way analyses of variance showed that: (a) there was a significant difference between the four groups on Day $1(\mathrm{~F}=12.6, \mathrm{df}=3 / 12, \mathrm{p}<.01)$; (b) there was no significant difference between Groups $\mathrm{S}, \mathrm{M}$, and $\mathrm{L}$ on Day $1(\mathrm{~F}<1)$; and (c) there was no significant difference between the four groups on Day $2(F<1)$. Taken together, these analyses reveal that on Day 1 , drugged Ss remained in the home cage significantly longer than did the controls, but after the effects of scopolamine had disappeared on Day 2, Ss did not differ in retreat time.

The preliminary finding that rats refused to enter the chamber unless rather stringent procedures (see method) were employed, supports the idea that the novel chamber elicited fear which in turn motivated avoidance. Furthermore, it seems reasonable to conclude that this fear habituated, at least in part, since control Ss remained in the chamber for $65 \%$ of the session time on both days of the experiment (cf. Welker, 1957, 1959; Valle, 1972). Thus, the finding that drugged rats remained in the chamber for only $17 \%$ of the session time on Day 1 leads to the conclusion that fear, as measured by retreat time, fails to habituate in rats under

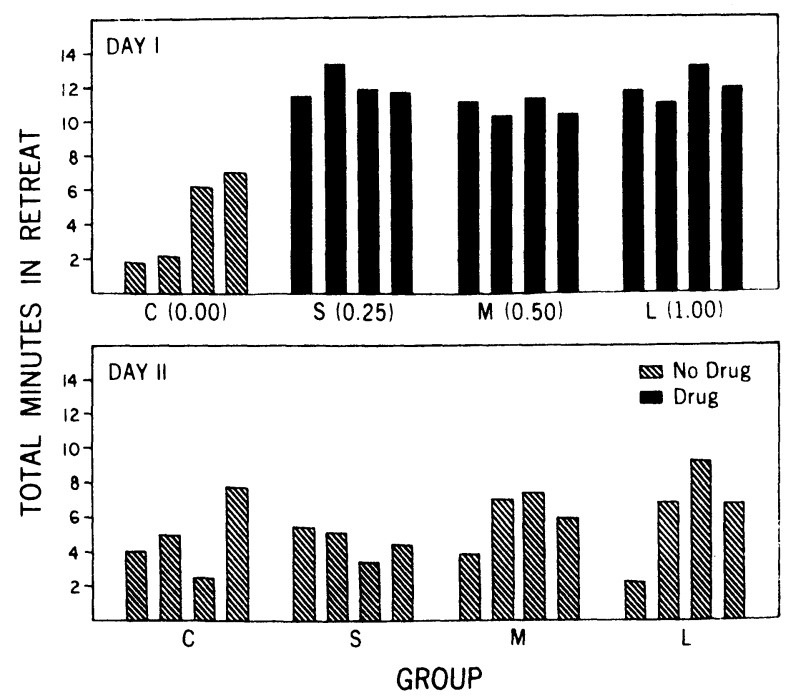

Fig. 1. Total number of minutes each $S$ remained in retreat during Days 1 and 2.

the influence of scopolamine. This conclusion is consistent with the suggestion that anticholinergic drugs impair inhibition of an excitatory system within the brain (Carlton, 1963).

Behavioral Observations. There were no striking differences between the behavior of drugged and control Ss either in terms of frequency or type of behavior displayed while in the exploratory chamber. The total frequency of observations during the 14-min session was divided into seven 2-min intervals, which served as the basis for the statistical analyses. A separate 4 by 2 by 7 analysis of variance was computed for each behavior. One variable was dosage, the second day, and the third was within-session time. The second and third variables involved repeated measures. Table 1 , shows the means and relative frequency of the seven behaviors for each group on Days 1 and 2. The total of the seven behaviors

Table 1

Means and Relative Frequency of Seven Behaviors for Each Group on Days 1 and 2

\begin{tabular}{|c|c|c|c|c|c|c|c|c|}
\hline \multirow{3}{*}{$\begin{array}{c}\text { Behavior } \\
\mathrm{Gm}\end{array}$} & \multicolumn{2}{|c|}{ Group C } & \multicolumn{2}{|c|}{ Group S } & \multicolumn{2}{|c|}{ Group M } & \multicolumn{2}{|c|}{ Group L } \\
\hline & & & & & & & & \\
\hline & 283 & $(.37)$ & 82 & $(.48)$ & 119 & (.44) & 74 & $(.48)$ \\
\hline Lo & 100 & $(.13)$ & 28 & $(.17)$ & 41 & (.15) & 29 & (.19) \\
\hline Sc & 162 & $(.21)$ & 35 & $(.17)$ & 61 & $(.22)$ & 21 & (.14) \\
\hline $\mathrm{Ob}$ & 124 & $(.16)$ & 37 & $(.16)$ & 42 & (.15) & 29 & (.19) \\
\hline Fr & 13 & $(.04)$ & 0 & $(.00)$ & 5 & (.03) & 0 & $(.00)$ \\
\hline $\mathrm{Gr}$ & 28 & $(.04)$ & 0 & $(.00)$ & 0 & $(.00)$ & 0 & $(.00)$ \\
\hline $\mathrm{Ch}$ & 55 & $(.07)$ & 4 & $(.02)$ & 1 & $(.01)$ & 0 & $(.00)$ \\
\hline \multirow[t]{2}{*}{ Total } & 765 & & 186 & & 269 & & 153 & \\
\hline & & & & & & & & \\
\hline $\mathrm{Gm}$ & 224 & $(.30)$ & 286 & $(.36)$ & 246 & $(.35)$ & 230 & $(.34)$ \\
\hline Lo & 88 & $(.12)$ & 119 & $(.15)$ & 107 & (.15) & 92 & (.14) \\
\hline $\mathrm{Sc}$ & 136 & $(.18)$ & 138 & $(.18)$ & 87 & (.12) & 127 & (.19) \\
\hline $\mathrm{Ob}$ & 129 & $(.17)$ & 188 & $(.24)$ & 136 & (.19) & 115 & (.17) \\
\hline Fr & 21 & $(.03)$ & 13 & $(.02)$ & 51 & (.07) & 37 & (.06) \\
\hline $\mathrm{Gr}$ & 41 & $(.05)$ & 10 & $(.01)$ & 25 & $(.04)$ & 15 & $(.02)$ \\
\hline $\mathrm{Ch}$ & 117 & $(.15)$ & 32 & $(.04)$ & 55 & (.08) & 50 & (.08) \\
\hline Total & 756 & & 786 & & 707 & & 666 & \\
\hline
\end{tabular}


Table 2

Means and Relative Frequency of Seven Behaviors for Each Group on Days 1 and 2

\begin{tabular}{|c|c|c|c|c|}
\hline \multirow{3}{*}{$\begin{array}{l}\text { Behavior } \\
\text { Exploratory }\end{array}$} & \multicolumn{2}{|c|}{ Group C } & \multicolumn{2}{|c|}{ Group D } \\
\hline & \multicolumn{4}{|c|}{ Day 1} \\
\hline & & & & \\
\hline $\mathrm{Gm}$ & 495 & $(.36)$ & 868 & $(.63)$ \\
\hline Lo & 111 & $(.08)$ & 136 & $(.10)$ \\
\hline $\mathrm{Sc}$ & 173 & (.13) & 125 & $(.09)$ \\
\hline $\mathrm{Ob}$ & 104 & $\begin{array}{c}(.07) \\
.64\end{array}$ & 144 & $\begin{array}{c}(.10) \\
.92\end{array}$ \\
\hline \multicolumn{5}{|l|}{ Terminal } \\
\hline Fr & 431 & $(.31)$ & 103 & $(.06)$ \\
\hline $\mathrm{Gr}$ & 24 & $(.02)$ & 1 & $(.01)$ \\
\hline $\mathrm{Ch}$ & 39 & $\begin{array}{c}(.03) \\
.36\end{array}$ & 2 & $\begin{array}{c}(.01) \\
.08\end{array}$ \\
\hline \multirow[t]{2}{*}{ Total } & 1377 & & 1379 & \\
\hline & \multicolumn{4}{|c|}{ Day 2} \\
\hline \multicolumn{5}{|l|}{ Exploratory } \\
\hline $\mathrm{Gm}$ & 266 & (.19) & 551 & $(.39)$ \\
\hline Lo & 60 & $(.03)$ & 172 & $(.12)$ \\
\hline $\mathrm{Sc}$ & 83 & $(.06)$ & 263 & (.19) \\
\hline \multirow[t]{2}{*}{$\mathrm{Ob}$} & 56 & $(.04)$ & 148 & $(.10)$ \\
\hline & & .32 & & .80 \\
\hline \multicolumn{5}{|l|}{ Terminal } \\
\hline Fr & 863 & $(.62)$ & 83 & $(.06)$ \\
\hline $\mathrm{Gr}$ & 55 & $(.03)$ & 70 & $(.05)$ \\
\hline \multirow[t]{2}{*}{$\mathrm{Ch}$} & 2 & $(.03)$ & 125 & $(.09)$ \\
\hline & & .68 & & .20 \\
\hline Total & 1385 & & 1412 & \\
\hline
\end{tabular}

is less for the three drugged groups than the control group on Day 1, but these differences were not significant in any of the behavioral categories $\mathbf{1}$; only $\mathrm{Gm}$ and $\mathrm{Ob}$ approached significance (Dosage by Day interaction for $\mathrm{Gm}$ and $\mathrm{Ob}$, respectively, $\mathrm{F}=3.01, \mathrm{~F}=$ 3.19 , $\mathrm{df}=3 / 16, .10>\mathrm{p}>.05)$. On Day 2 , the groups showed similar amounts of total behavior and an increase from Day 1 in $\mathrm{Gm}(\mathrm{F}=10.2$, $\mathrm{df}=1 / 16$, $\mathrm{p}<.01)$, Lo $(\mathrm{F}=15.9$, df $=1 / 16, \mathrm{p}<.01)$ and $\mathrm{Ob}(\mathrm{F}=$ 25.8 , df $=1 / 16, p<.01$ ) behaviors. On Days 1 and 2 , all four groups showed a within session decrease in $\mathrm{Gm}(\mathrm{F}=$ 13.9, $\mathrm{df}=6 / 69 ; \mathrm{p}<.01)$ and Lo $(\mathrm{F}=11.5, \mathrm{df}=6 / 69$, $\mathrm{p}<.01)$, but a within session increase in $\mathrm{Ch}(\mathrm{F}=3.65$, $\mathrm{df}=6 / 96, \mathrm{p}<.01)$ and no change in $\mathrm{Ob}, \mathrm{Sc}, \mathrm{Fr}$, and $\mathrm{Gr}$ (all $\mathrm{F}<1$ ).

These behavioral results show that scopolamine did not significantly interfere with the exploratory behavior of drugged rats when inside the chamber. Both drugged and control animals showed similar sequences of behavior on both days of the experiment: animals would initially locomote, contact objects, scan, and show general motor behavior, but as the session time increased, locomotion and general motor behavior decreased, while animals continued to contact objects, scan, and chew various parts of the chamber; animals showed very little freezing or grooming.

\section{Summary}

The results of this experiment show that reduced cholinergic activity impaired the habituation of fear, indicated by the drugged Ss' greater retreat time on
Day 1, but did not interfere with the behavior of drugged Ss when they were inside the chamber. After the effects of scopolamine had dissipated on Day 2, the animals did not differ either in terms of retreat time or behavior. These results are interpreted to mean that the cholinergic system inhibits an activating system within the brain (Carlton, 1963), but may not act to inhibit motor responses.

\section{EXPERIMENT II FORCED EXPLORATION}

The purpose of Experiment II was to test the idea that the cholinergic system mediates the habituation of behavioral responding, by measuring the effects of scopolamine on behavior that typically habituates under forced exploratory conditions. As in Experiment I, a 2-day procedure was used, with drug administration on Day 1 only, and behavior was described by means of seven behavioral categories.

\section{Method}

Subjects and Apparatus. Ss were eight naive male hooded rats of the Long-Evans strain, whose mean weight was $335 \mathrm{~g}$ at the start of the experiment. The breeding, taming, and maintenance procedures were identical to those used in Experiment I. The apparatus was the same as that used in Experiment I, except that the entry door remained closed at all times.

Procedure. One day prior to the experiment, all Ss were given a normal saline injection and returned to their home cages.

Test Day 1. The animals were randomly assigned a normal saline injection or a scopolamine hydrobromide $(0.5 \mathrm{mg} / \mathrm{kg}$ IP) injection. Each rat was returned to its home cage after injection, where it remained for $20 \mathrm{~min}$. It was then carried in its home cage to the testing. room and placed directly into the chamber for the 14-min test session.

Test Day 2. The procedure was the same as that used on Test Day 1, except that no injections were given. There were four Ss in each dosage level. The two dosage groups were designated Group C (con trol) and Group D (drug).

The response categories, tabulation and statistical procedures were identical to those used in Experiment $I$.

\section{Results and Discussion}

In contrast to the behavior of rats under free exploratory conditions, the behavior or rats under forced conditions can be divided into two classes: the exploratory behaviors, which are the activities that occur earlier in the sessions, and the terminal behaviors, which occur later in the sessions. Table 2 shows the means and relative frequency of each of the exploratory and terminal behaviors for both groups on Days 1 and 2 . Group C showed more exploratory behavior on Day 1 (64\%) but more terminal behavior on Day 2 (68\%). In contrast, Group D showed more exploratory behavior on both days of the experiment ( $92 \%$ on Day 1 and $80 \%$ on Day 2). However, of the exploratory behaviors, Group D only showed more $\mathrm{Gm}(63 \%$ on Day 1 and $39 \%$ on Day 2) and did not differ from Group C in either Lo, Sc, or Ob behaviors.

Exploratory Behaviors. Figure 2 demonstrates the 
within session change in mean frequency of $\mathrm{Gm}$ for both groups on Days 1 and 2. While both groups showed more $\mathrm{Gm}$ on Day 1 than on Day $2(\mathrm{~F}=16.2$, df $=1 / 6$, $\mathrm{p}<.01$ ), the drugged group showed more $\mathrm{Gm}$ overall than did the control group $(F=53.6, d f=1 / 6, p<.01)$. The control group showed a greater within session decrease in $\mathrm{Gm}$ than did the drugged group (Dosage by Time interaction, $F=3.98, \mathrm{df}=6 / 36, \mathrm{p}<.01$ ). Subsequent analyses revealed that: (a) on Day 1 , Group C showed a within session decrease in $\mathrm{Gm}$, while Group D showed continuous $\mathrm{Gm}$ behavior (Dosage by Time interaction, $\mathrm{F}=2.40, \mathrm{df}=6 / 36, \mathrm{p}<.05)$; (b) on Day 2, both groups showed a within session decrease in $\mathrm{Gm}(\mathrm{F}=14.0, \mathrm{df}=6 / 36, \mathrm{p}<.01)$ and did not significantly differ in amount of $\mathrm{Gm}(\mathrm{F}=3.12$, df $=1 / 6$, $\mathrm{p}>.05)$.

The within session change in mean frequency of Lo, $\mathrm{Sc}$, and $\mathrm{Ob}$ are shown in Fig. 3 for both groups on Days 1 and 2. The groups showed similar amounts of Lo, Sc, and $\mathrm{Ob}$ on Day 1, but on Day 2, the drugged group showed more of each of these behaviors (Dosage by Day interaction for Lo, $\mathrm{Sc}$, and $\mathrm{Ob}$, respectively, $\mathrm{F}=9.9, \mathrm{~F}=$ $6.39, \mathrm{~F}=6.04, \mathrm{df}=6 / 36, \mathrm{p}<.05)$. Both groups showed a within session decrease in Lo, Sc, and $\mathrm{Ob}$ on Days 1 and 2 (for $\mathrm{Lo}, \mathrm{Sc}$, and $\mathrm{Ob}$, respectively, $\mathrm{F}=32.8, \mathrm{~F}=$ $6.82, \mathrm{~F}=5.71, \mathrm{df}=6 / 36, \mathrm{p}<.01)$.

Taken together, these results indicate that scopolamine produced a differential effect on exploratory behavior: drugged rats showed a within session decline in Lo, $\mathrm{Sc}$, and $\mathrm{Ob}$ behaviors as did the controls, but drugged rats also showed continuous $\mathrm{Gm}$ behavior. On Day 2, drugged rats showed greater frequency of Lo, Sc, and $\mathrm{Ob}$ behaviors than did the controls. These results illustrate further that the effects of scopolamine were twofold: the drug produced changes in performance on Day 1 as well as on Day 2 after the effect of the drug had dissipated.

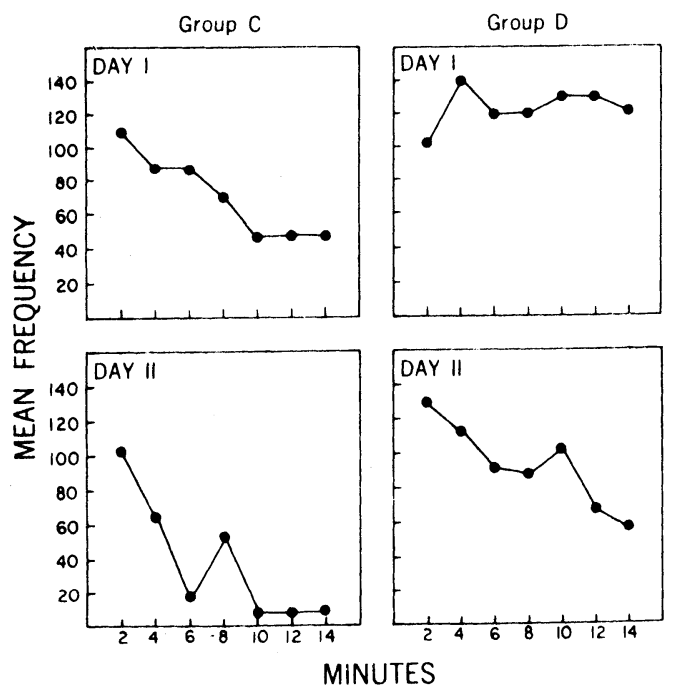

Fig. 2. Mean frequency of general motor behavior $(\mathrm{Gm})$ for both groups on Days 1 and 2.

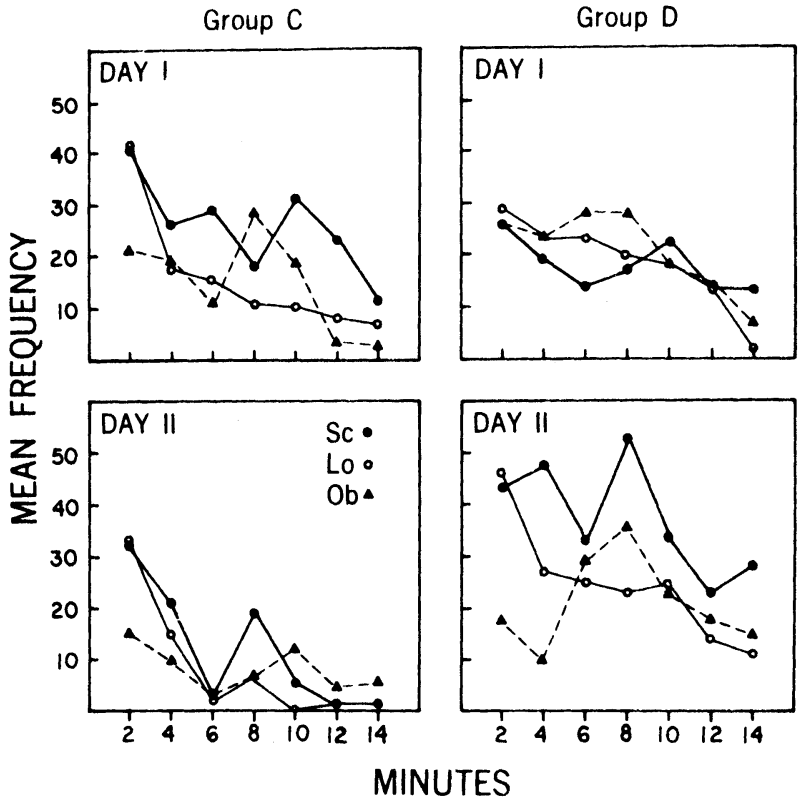

Fig. 3. Mean frequency of locomotion (Lo), scanning (Sc), and object contact $(\mathrm{Ob})$ for both groups on Days 1 and 2.

The finding that $\mathrm{Lo}, \mathrm{Sc}$, and $\mathrm{Ob}$ showed within session decreases in both control and drugged rats on Days 1 and 2 is considered to result from habituation to novel aspects of the testing situation. Each of these behaviors is a specific measure of exploratory activity: Lo is an index of movement within the chamber; $\mathrm{Sc}$ is a measure of attention directed to distant aspects of the chamber; $\mathrm{Ob}$ is an index of object exploration. Therefore, it is suggested that scopolamine does not interfere with habituation in the sense of response decrement (Thompson \& Spencer, 1966) as proposed by Carlton $(1968,1969,1971)$. This conclusion supports the results of Warburton and Groves (1969) who reported that scopolamine did not interfere with habituation of the acoustic startle response.

Carlton (1963, 1969) discussed a "disinhibitory" effect of scopolamine on behavioral output and others (Longo, 1966; Warburton \& Groves, 1969) have noted enhanced responding in rats under the effects of scopolamine. The present finding that $\mathrm{Gm}$, a general category of motor behavior, failed to show a within session decrease in drugged rats, is interpreted as evidence that scopolamine produced a disinhibitory effect on general motor behavior. By the latter half of the session, the drugged rats were locomoting, scanning, and contacting objects no more than controls, but continued to show general motor activity. It is therefore suggested that the drugged rats habituated to the novel aspects of the chamber to the same extent as controls, but remained in a state of heightened activity due to the disinhibitory effect of scopolamine on general motor output.

The aftereffects of scopolamine on Day 2 were found in the greater frequency of $\mathrm{Lo}, \mathrm{Sc}$, and $\mathrm{Ob}$ in previously 
drugged rats. These results suggest that experience does not transfer from the drugged to the nondrugged state. This phenomenon has been called "state-dependent" or "dissociated" learning (Berger \& Stein, 1969; Oliverio, 1968; Overton, 1966). To further test this idea, separate two-way analyses of variance were computed for each exploratory behavior comparing the control group's performance on Day 1 with the drugged group's performance on Day 2. The reasoning was that if Group D failed to transfer the experience of exposure in the drugged state on Day 1 to the nondrugged state on Day 2, then the group's performance on Day 2 should be similar to the control group's performance on Day 1 . The comparison showed no significant differences in terms of $\mathrm{Gm}(\mathrm{F}=3.61, \mathrm{df}=1 / 6, \mathrm{p}>.05), \mathrm{Lo}(\mathrm{F}=5.64$, $\mathrm{df}=1 / 6, \mathrm{p}>.05), \mathrm{Sc}(\mathrm{F}=1.19, \mathrm{df}=1 / 6, \mathrm{p}>.05)$ or $\mathrm{Ob}$ $(\mathrm{F}<1)$. These analyses confirm the view that scopolamine produces a drugged state in which learning is dissociated from learning in the nondrugged state.

Terminal Behaviors. Table 2 illustrates that Group C showed $31 \% \mathrm{Fr}$ on Day 1 and $62 \%$ on Day 2, while Group D showed little terminal behavior on either day of the experiment. Analyses of variance revealed that Group D showed less Fr on Days 1 and $2(\mathrm{~F}=20.8, \mathrm{df}=$ $1 / 6, p<.01$ ), and failed to show any within session increase in Fr as did Group $\mathrm{C}$ on both days of the experiment (Dosage by Time interaction, $\mathrm{F}=5.56 \mathrm{df}=$ $6 / 36, p<.01)$. Bindra and Spinner $(1958)$ showed that some rats were "freezers" while others were "nonfreezers." The "nonfreezers" tended to groom rather than to freeze. This variable was not controlled in the present study, since the emphasis was on the exploratory behaviors rather than terminal behaviors. Inspection of the data for individual Ss showed that two of the four control Ss were freezers, while only one of the four drugged Ss was a freezer. The nonfreezers in both groups tended to chew the apparatus or groom rather than freeze. Analyses of variance revealed that both groups showed more Gr on Day 2 than on Day 1 (F $=6.44, \mathrm{df}=1 / 6, \mathrm{p}<.05)$. Group $\mathrm{C}$ showed more $\mathrm{Ch}$ and a within session increase in $\mathrm{Ch}$ on Day 1 , whereas Group D showed more $\mathrm{Ch}$ and a within session increase in Ch on Day 2 (Dosage by Day by Time interaction, $F=$ $3.49, \mathrm{df}=6 / 36, \mathrm{p}<.01)$.

Summary. The major results of the present experiment show that reduced cholinergic activity: (1) produced a disinhibitory effect on $\mathrm{Gm}$ behavior in drugged rats; (2) failed to interfere with the habituation of either Lo, Sc, or Ob behaviors in drugged rats; and (3) produced a drugged state in which learning was dissociated from learning under a nondrugged state.

\section{GENERAL DISCUSSION}

The results and conclusions of the present experiments can be summarized as follows:

(1) The finding that drugged rats remained withdrawn from the chamber significantly longer than controls in Experiment I was interpreted to mean that scopolamine produced a disinhibitory effect on fear. This conclusion is consistent with the idea that the cholinergic system inhibits a general excitatory system within the brain (Carlton, 1963).

(2) The finding that drugged rats habituated locomotion, scanning, and object contact in Experiment II supports the results of Warburton and Groves (1969), who found that the acoustic startle response habituated in drugged rats. Taken together, these results are strong evidence against the idea that the cholinergic system mediates habituatory response inhibition as suggested by Carlton $(1968,1969,1971)$.

(3) In Experiment II, drugged rats showed continuous general motor behavior, which was attributed to the "disinhibitory" effect (Carlton, 1963; Longo, 1966) of scopolamine on general motor output. Carlton cites experiments showing that scopolamine produces increases in the frequency of such global measures of exploration as nose insertions (Wakeley \& O'Sullivan, 1969), light-reinforced barpressing (Carlton, 1966) and choice behavior (e.g., Leaton, 1968, 1969). These effects might be a consequence of this disinhibitory effect, rather than a lack of response habituation as hypothesized by Carlton and others.

(4) On the second day of Experiment II, previously drugged rats behaved as if they had not received the prior exposure on Day 1, which was interpreted to mean that the effects of scopolamine are "state-dependent" (cf. Berger \& Stein, 1969). The state-dependent effects of scopolamine may account for the results of Carlton and Vogel (1965) who also used a two-day procedure with drug administration on the first day only, but relied solely on the second day as a test for the effects of prior habituation.

Thus, the combined results of the present experiments lead to the conclusion that there are at least two inhibitory mechanisms within the brain: one controlling the inhibition of increased motivational arousal (Experiment I) and general motor activity (Experiment II); and another controlling the inhibitory process underlying response habituation. The results of the present investigation found evidence that the cholinergic system functions as the first inhibitory mechanism but not as the second. Therefore, the idea that the cholinergic system inhibits a general excitatory system within the brain (Carlton, 1963) was supported by the present findings, but the further suggestion that this same inhibitory cholinergic system mediates behavioral response habituation (Carlton, 1968, 1969, 1971) was not supported.

\section{REFERENCES}

Berger, B. D., \& Stein, L. An analysis of the learning deficits produced by scopolamine. Psychopharmacologia, 1969, 14, 271-283.

Bindra, D., \& Spinner, N. Response to different degrees of novelty: The incidence of various activities. Journal of the Experimental Analysis of Behavior, 1958, 1, 341-350. 
Carlton, P. L. Cholinergic mechanisms in the control of behavior by the brain. Psychological Review, 1963, 70, 19-39.

Carlton, P. L. Scopolamine, amphetamine and light-reinforced responding. Psychonomic Science, 1966, 5, 347-348.

Carlton, P. L. Brain-acetylcholine and habituation. Progress in Brain Research, 1968, 28, 48-60.

Carlton, P. L. Brain-acetylcholine and inhibition. In J. T. Tapp (Ed.), Reinforcement and behavior. New York: Academic Press, 1969. Pp. 286-327.

Carlton, P. L., \& Markiewicz, B. Behavioral effects of atropine and scopolamine. In E. Furchtgott (Ed.), Pharmacological and biophysical agants and behavior. New York: Academic Press, 1971. Pp. 345-373.

Carlton, P. L., \& Vogel, J. R. Studies of the amnesic properties of scopolamine. Psychonomic Science, 1965, 3, 261-262.

Douglas, R. J., \& Isaacson, R. L. Spontaneous alternation and scopolamine. Psychonomic Science, 1966, 4, 283-284.

Grant, E. C., \& Mackintosh, J. H. A description of the socia postures of some laboratory rodents. Behaviour, 1963, 21 . 246-259.

Leaton, R. N. Effects of scopolamine on exploratory motivated behavior. Journal of Comparative \& Physiological Psychology, $1968,66,524-527$.

Leaton, R. N. Effects of scopolamine and methscopolamine on brightness discrimination reinforced by opportunity for exploration. Journal of Comparative \& Physiological Psychology, 1969, 1, 155-158.

Longo, V. G. Behavioral and electroencephalographic effects of atropine and related compounds. Pharmacological Review, 1966, 18, 965-996.

Magoun, H. W. The waking brain. (2nd ed.) Springfield, Illinois: Thomas, 1963.

Meyers, B., \& Domino, E. F. The effect of cholinergic blocking drugs on spontaneous alternation in rats. Archives of International Pharmacodynamics, 1964, 150, 525-529.

Oliverio, A. Effects of scopolamine on avoidance conditioning and habituation of mice. Psychopharmacologia, 1968, 12, 214-226.
Overton, D. A. State-dependent learning produced by depressant and a tropine-like drugs. Psychopharm acologia, 1966, 10, 7-31.

Squire, L. R. Effects of pretrial and posttrial administration of cholinergic and anticholinergic drugs on spontaneous alternation. Journal of Comparative \& Physiological Psychology, 1969, 1, 69-75.

Thompson, R. F., \& Spencer, W. A. Habituation: A model phenomenon for the study of neuronal substrates of behavior. Psychological Review, 1966, 73, 16-43.

Valle, F. P. Free and forced exploration in rats as a function of between- vs within-Ss design. Psychonomic Science, 1972, 29 11-13.

Wakeley, H. G., \& O'Sullivan, D. Drug effects on mouse exploratory behavior. Psychonomic Science, 1969, 16, 27-28.

Warburton, D. M., \& Groves, P. M. The effects of scopolamine on habituation of acoustic startle in rats. Cummunications in Behavioral Biology, 1969, 3, 289-293.

Welker, W. I. "Free" versus "forced" exploration of a novel situation by rats. Psychological Reports, 1957, 3, 95-108.

Welker, W. I. Escape, exploratory, and food-seeking responses of rats in a novel situation. Journal of Comparative \& Physiological Psychology, 1959, 52, 106-111.

Welker, W. I. Analysis of sniffing of the albino rat. Behaviour, $1964,22,223-244$

\section{NOTE}

1. Drugged rats spent significantly less time in the chamber, but failed to show significantly less behavior than controls. This was due to large behavioral variability within both drugged and control groups.

(Received for publication January 21, 1974; accepted February 19, 1974.) 